\title{
Antecedent Contained Deletion in a Variable-Free Semantics
}

\author{
Pauline Jacobson \\ Brown University
}

\section{Background}

The point of departure for this paper is the hypothesis that surface structures directly receive a model-theoretic interpretation rather than being mapped into some other level of representation like LF. In particular, this paper will focus on the phenomenon of Antecedent Contained Deletion (hereafter, ACD), because this phenomenon has often been taken to necessitate a level of LF (see e.g., Sag, 1976; Williams, 1977; Larson and May, 1990). After first reviewing the apparent problem which $A C D$ poses for direct surface interpretation, I turn in Sec. 2 to a semantics which makes no essential use of variables. The basic idea of a variablefree semantics was proposed originally in Quine (1966), and its linguistic applications have been explored recently by, among others, Szabolcsi (1987, to appear), Hepple (1990), and Jacobson (1991b, 1992b). In Sec. 3 I argue that such an approach has considerable independent motivation - quite apart from the problem of ACD. In Sec. $4 \mathrm{I}$ then return to $\mathrm{ACD}$, to show that with a variable-free semantics it is trivial to account for this phenomenon under direct surface interpretation.

Within the literature on VP Deletion, we can distinguish two main approaches. The first - which we will refer to as the LF approach - claims that in an ordinary VP Deletion case like (1) the antecedent VP is first translated into some kind of LF (such as that shown in (2)) and this is then copied into the position of the "missing" VP following will:

(1) John will run, and Bill will too.

(2) John will [vp $\lambda x[r u n '(x)]]$ and Bill will [vp e] too.

This general approach is proposed in Sag (1976) (although Sag phrased this in terms of deletion instead of copying), Williams (1977), Larson and May (1990), and others. The second proposal - call it the direct interpretation approach - claims that the meaning of the antecedent VP is directly supplied as the argument of the meaning of the auxiliary; this is proposed in, among others, Keenan (1971), Ladusaw (1979), Partee and Bach (1981), and Fodor and Sag (1982). Thus in (1) the property of running is salient in the discourse context, and so is picked up as the missing argument of the meaning of the auxiliary.

\footnotetext{
* I would like to thank Mary Dalrymple, David Dowty, Mark Hepple, Robert May, Barbara Partee, and Matthew Stone for helpful comments and discussion. This research was supported by NSF grant BNS-9014676.
} 


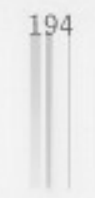

Notice that under the direct interpretation approach, there is no particular reason why the missing property should have to be the meaning of some overt VP as opposed to any contextually salient property. In other words, it does not follow immediately from this approach that this should be a case of what Hankamer and Sag (1976) called surface anaphora. Space precludes a detailed discussion of this issue here; suffice it to note that a good deal of literature has indeed challenged the claim that this is truly surface anaphora. For a recent discussion of relevance, see Dalrymple, Shieber, and Pereira (1991). in (3):

But one of the biggest challenges to direct interpretation comes from $\mathrm{ACD}$, as

(3) John will read every book which Bill (also) will.

According to traditional wisdom, the problem is roughly as follows. We need to find some salient property to be picked up by the meaning of will. But in (3) there is no way to find the relevant property. If we try to pick up the meaning of the matrix VP the result is an infinite regress, since no meaning is assigned to this VP until will finds its complement. The LF view, on the other hand, has no problem. Under this view the object NP is raised at LF, leaving a variable in the position following read. The LF for the matrix VP can then be copied into the position of the empty VP following will.

Nonetheless, Cormack (1985), Evans (1988), and Jacobson (1991a, 1992a) have all pointed out that given the general treatment of extraction in Categorial Grammar, this case of ACD is actually straightforward under direct interpretation. The fallacy in the line of reasoning above is that will need not in fact find a VPtype meaning (i.e., a property) as its complement. Rather, it can function compose with some salient 2-place relation. In fact, this is exactly the type of meaning needed here, since will is within a relative clause. Put differently, the claim is that the meaning of (3) is put together in essentially the same way as is the meaning of a non-elliptical case like (4):

(4) John will read every book which Bill will (also) read.

In a Categorial account of extraction such as Steedman (1987) the meaning of read in (4) function composes with the meaning of will, and the meaning of will-read function composes with the type-lifted meaning of Bill. The result is that the expression Bill will read denotes a property, and is thus of the right type to serve as argument of the relative pronoun. But notice that the meaning of (3) can therefore be put together in essentially the same way. Here will' picks up some salient twoplace relation - in this case read'- and it function composes with this; the rest of the composition works exactly as in the case of (4). The key here is that there is no need for an LF VP with a variable in object position precisely because this account of the semantics of relative clauses makes no use of a variable or a trace in object 
position in general. What this paper will show is that in a variable-free semantics, this basic idea can be extended to other cases. Moreover, Sag (1976) discussed some interesting interactions of scope and ACD. Space precludes a discussion of this here, but Cormack (1985) and Jacobson (1991a, 1992a) show that these interactions also follow equally well under the TVP ellipsis approach.

Note, then, that the claim here is that Antecedent Contained Deletion is somewhat of a misnomer - (3) is just a special case of the more general phenomenon of TVP ellipsis. In an antecedent containment case like (3) the "missing" TVP just happens to be within an NP which is the object of the antecedent TVP. But if this general kind of analysis is right, then this shouldn't be necessary - we should find other cases of TVP ellipsis, including those where the missing 2-place relation is picked up from a TVP in another sentence. And indeed, Evans (1988) noted that this expectation is borne out; TVP is possible in cases like (5)-(7) (where (5) and (6) are from Evans, 1988):

(5) I know which student Al likes, and I know which student Mary doesn't.

(6) Bagels, I like. Donuts, I don't.

(7) John was supposed to read several books this semester. But the only one that he actually did was The Brothers Karamazov.

Such sentences are especially interesting in that they challenge another argument for the LF view put forth in Sag (1976). Thus Sag further motivated the LF theory by claiming that there is a constraint to the effect that the variable in the "copied" VP must be bound by the same material as binds the variable in the antecedent VP. This constraint is designed to account for the ungrammaticality of cases like (8):

(8) *Which book will John read? I don't know - which book will Bill?

In (8), the LF for the first VP will be $\operatorname{read}^{\prime}(x)$ (or, $\left.\lambda y\left[\operatorname{read}^{\prime}(x)(y)\right]\right)$ ). If this is copied in to the empty position following Bill in the second sentence, then $x$ in the second sentence will be bound by a different occurrence of which book as binds this in the antecedent VP; Sag's constraint thus rules this out. As discussed in detail in Partee and Bach (1981), such a constraint would be difficult to account for under a purely semantic approach since it relies on formal properties of LF; the reader is referred to their paper for a detailed exposition of the problem. Notice, though, that Sag's constraint will also incorrectly rule out all of the cases in (5)-(7) and thus the explanation for the impossibility of $(8)$ must lie elsewhere. I have no account of this; Evans (1988) speculates that its ungrammaticality has to do with the presence of subject-aux inversion (thus contrast (8) with the grammatical (5)). To be sure, there are other cases in which TVP ellipsis is impossible which remain 
unexplained here; without additional context (9), for example, cannot have the meaning in $(10): 1$

(9) Every man that Sue did kissed Mary.

(10) Every man that Sue kissed kissed Mary.

Thus while TVP ellipsis is certainly "fussier" than ordinary VP ellipsis, Sag's generalization appears to be incorrect. As we would expect under the analysis here, the "missing" 2-place relation can be supplied by the meaning of a TVP even in another sentence as in (6) and (7), and so the direct interpretation theory is quite viable.

Yet despite the fact that cases like (3) and (5)-(7) are quite naturally accounted for by the TVP ellipsis analysis, there remains one apparent problem for this account. As Cormack (1985) points out, it would appear that such an account will not extend to cases like (11) (discussed originally in Bouton, 1970):

(11) a. John kissed every woman who wanted him to.

b. John kissed every woman who thought he would.

The problem here is that there is no grammatical paraphrase in which we substitute in an overt transitive verb. If, for example, (11b) involves TVP ellipsis, then we would expect to be able to substitute in the ordinary transitive verb kiss. But doing this yields the completely ungrammatical sentence in (12); to get the grammatical paraphrase we need to substitute in a full VP, as in (13):

(12) *John kissed every woman who thought he would kiss.

(13) John kissed every woman who thought he would kiss her.

At first blush, then, it would appear that (11) cannot be an instance of TVP ellipsis, but is instead full VP ellipsis. But if this is the case, then we are back to the

\footnotetext{
${ }^{1}$ Robert May has pointed out to me that another potential problem with the TVP ellipsis analysis is that it provides no explanation for the strangeness of (i), since did' should be able to pick up the meaning said":
}

?*John said that Bill did that Sam left.

While I do not know why (i) is somewhat bad, two comments are in order. First, it is not clear to me that this is truly ungrammatical. Second, it is not clear how any thoery would account for the strangeness of (i), since in any case it should be possible as an instance of pseudo-gapping (Levin, 1979) as in (ii):

(ii) John said that Mary left, and Bill did that Sam left.

(I thank David Dowty for this point.) In fact, pseudo-gapping itself might also be subsumed under TVP ellipsis. 
original problem. If the missing complement of would in (11b), for example, must be a property, then that property has to be made salient somehow. But it can't be derived from the meaning of the matrix VP, since this leads to an infinite regress. In other words, while the simple case of ACD in (3) is easily handled under direct interpretation, (11) appears not to be.

The remainder of this paper is devoted to showing that the problem of (11) is only apparent - under a completely variable-free semantics the analysis of (11) falls right out, and it too is an instance of TVP ellipsis. First, however, I will develop one implementation of a variable-free approach, and will then show that this has considerable independent motivation, quite apart from the problem of $\mathrm{ACD}$; we return to (11) in Sec. 4.

\section{A Variable-Free Semantics}

Consider the three sentences in (14):

(14) a. Every man told every woman that [s2 Tom thinks [s3 Jo likes Sue]]

b. Every manj told every woman that [ $\mathrm{s}_{2}$ Tom thinks [ $\mathrm{S}_{3}$ he $\mathrm{e}_{\mathrm{i}}$ likes Sue]]

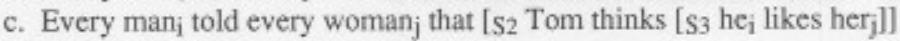

The standard approach to variables does have a certain appeal. First, under this approach the most deeply embedded $\mathrm{S}$ in all three of these cases has the same kind of meaning: each of these denotes a function from assignment functions to propositions. This would appear to be a happy result, since constituents containing pronouns and corresponding constituents without pronouns have essentially the same syntactic distribution - we return to this point in Sec. 5. In a related vein, the standard approach allows for uniform combinatorics here - in all three cases in (14) the meaning of $S_{3}$ combines with the meaning of thinks in the same way.

But despite these advantages, there are also certain problems with the standard approach. The first concerns the status of variables as model-theoretic objects. If the meaning of, say, a sentence is a function from assignment functions to propositions then the assignment functions must themselves be model-theoretic objects, and this in turn means that the variables also are. While it is difficult to demonstrate that such a result is incorrect, it is surely not a particularly pleasant one. Moreover, under most theories making use of variables, each English pronoun must "come" with an index, which means that there are an infinite number of lexical items (he $e_{1}, h e_{2}$, etc.). This in itself may not be problematic, but what is suspicious is that each such lexical item makes exactly the same contribution to the meaning of a sentence. Both of these points are discussed in some detail in Landman and Moerdijk (1983).

Thus an altemative is a variable-free semantics of the sort first proposed in Quine (1966) and explored within the linguistic literature more recently in Szabolcsi (1987, to appear), Hepple (1990), Jacobson (1991b, 1992b), and others. (See also 


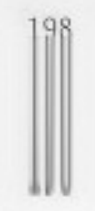

Dowty (1992) for a comparison of approaches with and without variables, and for discussion of various variable-free approaches.) The idea here is that while $\mathrm{S}_{3}$ in (14a) denotes a proposition, $S_{3}$ in (14b) denotes a function from individuals to propositions (i.e., a property). In (14c) $S_{3}$ denotes a 2-place relation.

There are a variety of ways that this basic program can be implemented; I will discuss just one here which is the one developed in Jacobson (1991b, 1992b). First, I will assume that there is a single pronoun he in English, and that its meaning denotes the identity function on individuals. (A similar account of the meaning of reflexives is developed in Pollard and Sag, 1982; since Pollard and Sag deal only with reflexives and I will deal here only with ordinary pronouns I will not attempt a detailed comparison of the two approaches.) Strictly speaking, the meaning of he is presumably the identity function on male individuals, and so such a pronoun does in fact make some contribution to the meaning of the larger constituent in which it occurs, but I will systematically ignore gender here. Second, we will allow for additional combinatorics besides just functional application. Take, for example, a case like (15):

(15) Every $\operatorname{man}_{\mathrm{i}}$ believes Mary likes himi.

The meaning of him is the identity function, and so this will function compose with the meaning of like such that the VP likes him means simply like'. Further, I will assume that the meaning of this VP function composes with the type-lifted meaning of Mary, and so the meaning of the embedded S is the property: $\lambda x$ [like $(x)(m)]$. In cases involving two or more pronouns additional combinatorics will be needed, but I will not deal with these here (for a brief discussion of some such cases, see Jacobson, 1992b).

Before turning to the question of how it is that the pronoun is ultimately "bound", it should be noted that I will be assuming that free pronouns are just like bound ones. In other words, take a sentence with a free pronoun such as (16):

\section{(16) Mary likes him.}

We can assume that the meaning of this is composed in exactly the way discussed above; the consequence of this is that (16) denotes not a proposition but rather a property. Of course in order to extract information from such a sentence a listener needs to construct a proposition; it is reasonable to assume that this is generally done simply by applying this property to some contextually salient individual.

We can now turn to the question of just how the pronoun him in (15) is ultimately bound by every man. While there are again a variety of ways to effect binding, I will assume that the binding of this pronouns it he result of a type-shift operation on the verb believes. I will call this operation $z$; this operation is as follows: 
(17) Let $\mathrm{f}$ be a function of type $\langle\mathrm{X},\langle\mathrm{e}, \mathrm{Y}>>$. Then $z(\mathrm{f})$ is a function of type $<<e, X>,<e, Y \gg>$, where $z(f)=\lambda g[\lambda x[f(g(x))(x)]]$ (for $g$ a variable of type $<e, X>$ ).

Let $\alpha_{1}$ be an expression of syntactic category $\mathrm{A}$ with a meaning of type $\langle\mathrm{X},\langle\mathrm{e}, \mathrm{Y}\rangle\rangle$. Then there is a homophonous expression $\alpha_{2}$ which is also of syntactic category $\mathrm{A}$, where $\alpha_{2}^{\prime}=z\left(\alpha_{1}^{\prime}\right)$.

((17) needs to be generalized for the case of 3-place verbs; see Jacobson (1992b).)

Consider, then, an ordinary transitive verb like love, which denotes the 2place relation (between individuals) love'. This can shift by into a homophonous expression of the same syntactic category which denotes the relation $z$ (love'), where $z$ (love') is a relation between individuals and functions from individuals to individuals, such that $\mathrm{x}$ stands in the $z$ (love') relation to a function $\mathrm{f}$ (of type $\langle\mathrm{e}, \mathrm{e}\rangle$ ) just in case $\mathrm{x}$ stands in the love' relation to $\mathrm{f}(\mathrm{x})$. Similarly, $z$ (believe') is a relation between individuals and properties such that $\mathrm{x}$ stands in the $z$ (believe') relation to $\mathrm{P}$ just in case $\mathrm{x}$ stands in the believe' relation to $\mathrm{P}(\mathrm{x})$.

The variable-binding in (15) is now straightforward; believe here shifts by (17), and so its meaning is $z$ (believe'). Recall that the embedded S in (15) denotes the property $\lambda x$ [likes' $(x)(m)]$. This can thus occur as argument of $z$ (believe'), and so the VP believe Mary likes him will denote the property $\lambda y$ [believe' $($ like' $(y)(m))(y)]$; this is sketched in (18):

(18) believe-Mary-likes-him' $=z$ (believe' $)\left(\lambda \times\left[\right.\right.$ likes $\left.\left.^{\prime}(\mathrm{x})(\mathrm{m})\right]\right)=$

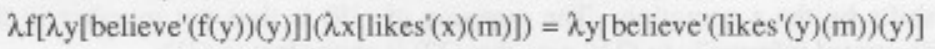

This property will then occur as argument of the subject NP.

\section{Independent Motivation}

\subsection{Functional Questions}

Before returning to $\mathrm{ACD}$, we will briefly consider some independent motivation both for a variable-free semantics in general and for this particular implementation; Jacobson (1992b) provides additional motivation centering on paycheck pronouns, Bach-Peters sentences, and their interaction with weak crossover. The first piece of independent motivation to be considered here centers on functional questions such as (19) and (20) under the reading where his mother is an appropriate answer;

(19) Who does every Englishman love? His mother.

(20) Which of his relatives does every Englishman admire most? His mother. 


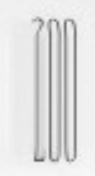

Groenendijk and Stokhof (1983) and Engdahl (1986) analyze these in such a way that the gap has a complex meaning. Thus, they assume a semantics with variables, and translate the gap not as a simple variable over individuals but rather as a variable over functions of type $\langle e, e\rangle$ applied to a variable over individuals. The meaning of (19), then, can be represented roughly as in (21):

(21) what is the function f: every-Englishman' $\left(\lambda \mathrm{f}\left[\right.\right.$ love' $\left.\left.^{\prime}(\mathrm{f}(\mathrm{x}))(\mathrm{x})\right]\right)$

(for $f$ a function of variable over functions of type $<e, e>$ )

Note that this is rather informal; a more complete account of (19) depends on one's analysis of the semantics of questions in general which is orthogonal to the points here. For our purposes, it is sufficient to note that the G\&S/Engdahl analysis assigns the meaning in (22) to the constituent every Englishman love; this meaning then presumably occurs as argument of the meaning of the question pronoun who:

$$
\text { every-Englishman-love' }=\text { every-Englishman' }\left(\lambda f\left[\text { love' }^{\prime}(\mathrm{f}(\mathrm{x}))(\mathrm{x})\right]\right)
$$

I assume that the basic idea behind the G\&S/Engdahl analysis is correct. Notice, however, that this particular implementation is incompatible with Categorial accounts of extraction which assume that a gap is simply a missing argument rather than corresponding to a trace or some other syntactic element which can be assigned a meaning. In other words, if a gap is nothing more than a missing argument, then it could not have the kind of complex meaning needed under this implementation. In view of this, I proposed in Jacobson (1991b, 1992c) that in (19) love typeshifts by the $z$ operation. The meaning of (19) is thus put together in the way illustrated informally in (23); note that (23) is equivalent to (21):

$$
\text { what is the function } \mathrm{f} \text { : every-Englishman' }\left(z\left(\text { love }^{\prime}\right)(\mathrm{f})\right)
$$

The semantic composition of the constituent every Englishman love is shown in more detail in (24); love shifts by $z$ and then occurs as argument of the subject:

(24) every-Englishman' o $z($ love' $)=\lambda f[$ every-Englishman' $(z($ love' $)(f))]=$ $\lambda f$ every-Englishman' $(\lambda x[$ love' $(\mathrm{f}(\mathrm{x}))(\mathrm{x})])]$

As in the G\&S/Engdahl analysis, this then occurs as argument of the meaning of who.

The interesting thing about this approach to binding is that this allows us to treat the gap in a functional question just like any other gap. Here too it is simply a "missing" argument and - just like in an ordinary question - the meaning of the verb composes with the meaning of the subject. But once we have this type shift rule to account for functional questions, we have exactly the mechanism we need to do 
binding in general in a variable-free semantics. Incidentally, the existence of functional questions is one of the reasons why I do not adopt the approach to binding in Szabolcsi (to appear). In her implementation, the binding effect in a case like (15) is built into the meaning of the pronoun; the pronoun is, in essence, an argument reducer which is waiting to be bound. However, by building the binding effect into the meaning of the pronoun there is no obvious way to generalize this to functional questions. ${ }^{2}$

\subsection{Answers to Functional Questions}

A second argument for a variable-free semantics in general concerns the fact that his mother is a perfectly appropriate answer to a functional question like (19). Under the standard account of variables this is somewhat surprising. After all, under such an account his mother denotes - relative to some way to assign values to variables - simply an individual, and so it is hard to see why it should serve as the answer to a question which asks for the identity of a function from individuals to individuals. Note, though, that under the variable-free approach it follows immediately that this is an appropriate answer to this question. Since his is a pronoun it denotes only the identity function, and so its meaning functioncomposes with mother'; this means that his mother simply denotes the motherfunction. ${ }^{3}$ It thus follows that it is an appropriate answer to a functional question. (For related discussion, see Ginzburg, 1992.) Notice, incidentally, that this point goes through even if the particular mechanism for binding proposed here turns out to be wrong. Presumably his mother will denote the mother-function under almost any implementation of a variable-free semantics.

\footnotetext{
${ }^{2}$ Matthew Stone (personal communication) has pointed out to me that another way to effect binding in general is to build the binding into the meaning of the binder. Thus rather than having the operation $z$, one could have an operation mapping the ordinary generalized quantifier meaning of the NP every man into a second meaning: $\lambda R\left[\forall x\left(\operatorname{man}^{\prime}(x) \rightarrow R(x)(x)\right)\right]$ (for $R$ a variable of type $\langle e,<e, \downarrow>)$. Under this approach, the VP in (15) would denote a two-place relation which would occur as argument of the subject. Of course this, like the approach here, will need to be generalized to account for binders which are in object position, etc. I have not explored this approach in detail, but it would appear that it too would allow for an account of functional questions without having to assign a complex meaning to the gap.

${ }^{3}$ I am glossing over one complication which arises here due to the fact that his is a genitive. For simplicity, I am assuming that the lexical meaning of a relational noun like mother' is a function of type <e,<e, $1>>$. If it takes a PP object (as in mother of Bill) it then is an ordinary common noun of type <e, $>$. Presumably, however, it can also type-shift into an expression wanting : genitive NP to give an NP; call this mother 2 . I assume further that the meaning of mother 2 is $\lambda x[$ ty[mother-of $(x)(y)]]$ - this is thus the function mapping each individual into her/his unique mother (or what I have called above the mother-function). Thus in the case at hand his functioncomposes with the meaning of mother 2 ; since his' is only the identity function the result is again the function mapping each (male) individual into his unique mother.
} 


\subsection{Unexpected Binding in Copular Sentences}

A similar point can be made on the basis of unexpected binding in copular sentences. By way of background, let us take the semantics proposed in Williams (1983) and Partee (1985) for an ordinary specificational copular sentence such as (25):

(25) The woman who John loves the most is Mary.

Under the Williams/Partee approach, the specificational reading for (25) is one in which the first NP is predicational and the second is referential. To formalize this notion, Partee suggests that an ordinary individual-denoting NP (such as the woman who John loves the most) can type-shift to denote the singleton set containing this individual. Thus on its predicational reading, the meaning of the first NP in (25) is: $\lambda x\left[x=t y\left[\right.\right.$ woman' $^{\prime}(y)$ \& love-the-most $\left.\left.(y)(j)\right]\right]$. Moreover, be takes two arguments: one of type $\langle\mathrm{X}, \mathrm{t}\rangle$ and one of type $\mathrm{X}$. In a predicational copular sentence, the argument of type $\langle\mathrm{X}, \mathrm{t}\rangle$ is in second position; in a specificational copular sentence (such as (25) under the reading of concern here) the argument of type $\langle\mathrm{X}, \mathrm{t}\rangle$ is in first position. The meaning of be is such that (25) simply applies the function denoted by the first NP to the individual Mary'; this is shown in (26):

$$
\begin{gathered}
\left(25^{\prime}\right)=\lambda x\left[x=t y\left[\operatorname{woman}^{\prime}(y) \text { \& love-the-most' }(y)(j)\right]\right](m)= \\
m=t y\left[w_{\text {woman }}^{\prime}(y) \text { \& love-the-most }(y)(j)\right]
\end{gathered}
$$

Now consider (27), discussed originally in Geach (1962) and more recently in Hornstein (1984) (a related case is also discussed in Groenendijk and Stokhof, 1983):

(27) The woman who every Englishman ${ }_{i}$ loves the most is hisi mother.

Under the Williams/Partee semantics combined with the approach to binding suggested here, (27) is straightforward provided we make one additional assumption. This is that ordinary NPs can, in certain cases, have functional readings. In particular, assume that an ordinary NP like the woman who every Englishman loves can denote the (unique) function $\mathrm{f}$ (of type $<\mathrm{e}, \mathrm{e}>$ ) whose range is women and which is such that every Englishman $z$ (loves) f. More precisely, we will assume that functions of type $<e, e>$ have "individual correlates" (in the sense of Chierchia, 1984) such that we can speak of the unique individual which is a function of this type. Thus in its functional reading, the meaning of an NP like the 
woman who every Englishman loves can be represented very roughly as (28) where ${ }^{n}$ is Chierchia's nominalization operator) ${ }^{4}$

\section{(28) $\mathrm{t}^{\wedge} \mathrm{f}[$ every-Englishman'(z(love')(f)]}

Given this, (28) can type-shift into a predicative expression just as any other NP can under Partee's analysis, and so it will denote the function characterizing the singleton set containing this nominalized function. Since his mother denotes only the mother-function, the meaning for (27) is as represented in (29):

(29) $\lambda \mathrm{g}\left[\mathrm{g}=\hat{\imath} \mathrm{f} f\right.$ every-Englishman'(z(love')(f)]]( ${ }^{\wedge}$ mother') (for g a variable over nominalized functions from individuals to individuals

(Informally, then, (27) simply says that the mother-function is the unique function $\mathrm{f}$ such that every Englishman z(loves) f.) Notice that this type of analysis eliminates the need for any kind of "reconstruction" (as proposed in Hornstein, 1984) whereby the post-copular constituent is put into the position of the gap in order for every Englishman to bind the pronoun.

\subsection{Unexpected Inferences}

The final argument that we consider here for a variable-free approach and for this implementation centers on a range of cases involving unexpected inferences. This phenomenon is exemplified in (30) (discussed in, among others, Higginbotham (to appear), Chierchia (1990), Reinhart (1990), and Pollard and Sag (to appear)):

(30) a. Every Englishman believes whatever every Frenchman believes.

b. Every Frenchman believes that he $_{i}$ should drink red wine.

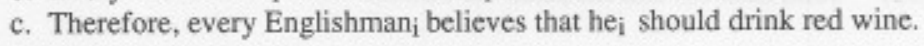

Under the standard view, believe takes a propositional complement, and so the complement in (30b) denotes an open proposition. Given this, (30c) does not follow from (30a) and (30b), but it is in fact a valid inference.

To account for this, Chierchia (1990) makes the following proposal. First, he takes it to be a lexical fact about believe that there are two verbs believe - one which I will for the moment call believe 1 and a second believe 2 . believe 1 denotes a relation between individuals and propositions, while believe 2 denotes a relation between individuals and properties. Moreover, their meanings are related by a meaning postulate which ensures that if an individual $\mathrm{x}$ stands in the believe 2

\footnotetext{
$4 \mathrm{I}$ ignore in (28) the fact that the range of the function must be the set of women. I also ignore the question of just how the meaning of this NP is put together so as to give this result.
} 
relation to a property $\mathrm{P}$ then $\mathrm{x}$ stands in the believe $e_{1}$ relation to $\mathrm{P}(\mathrm{x})$. The second part of Chierchia's proposal makes the standard assumption that the complement in (30b) translates as the open proposition $x$ should drink red wine. However, he posits a special rule to map the open proposition into a property by $\lambda$-abstracting over $\mathrm{x}$, so that this is mapped into the property $\lambda x[x$ should drink red wine]. We now have all the pieces to account for the inference here. All three sentences involve the verb believe 2 . Thus the first sentence says that every Englishman stands in the believe 2 relation to whatever property every Frenchman stands in, and the second sentence says that every Frenchman stands in the believe 2 relation to the property of being an $x$ who should drink red wine. From this (30c) follows.

But notice that these particular mechanics are all subsumed under the more general proposals here. First, Chierchia's believe ${ }_{2}^{\prime}$ is simply $z$ (believe') - the difference is that I am claiming that this is not a lexical property of believe per se, but rather that any expression can type-shift in this way to give the effect of binding. Second, in a variable-free approach we are spared from having to posit a special rule which maps an open proposition into a property. For here there is no such thing as an open proposition - since the embedded $S$ in (30b) contains a pronoun it necessarily denotes a property. The idea, then, is that these inferences are an instance of exactly the same phenomenon that we find in functional questions. And more generally, this is all subsumed under the general mechanisms for bound pronouns. 5

Chierchia did not hook this into a treatment of variables in general, since he sliced up the pie in a somewhat different fashion. Under his account, the unexpected inference here derives from a fact about believe. More specifically, he tries to motivate the existence of the two verbs believe by tying this in to the de re/ de se ambiguity found in sentences like (31) and discussed in, among others, Lewis (1979):

\section{(31) John believes that his pants are on fire.}

The de re reading is one where John may see himself with fiery pants in the mirror without realizing that it is indeed John who he is seeing; the de se reading is one where John believes that the fiery-pants property is self-ascribable. Thus Chierchia's idea is that what I have been calling believe I is de re believe, while believe $_{2}$ is de se believe. But Reinhart (1990) quite convincingly shows that the

\footnotetext{
${ }^{5}$ Note that the inference case here is another reason for preferring the type-shift operation $z$ over an account of variable-binding such as that of Szabolcsi (to appear) in which the binding effect is built into the meaning of a pronoun. The problem with the latter approach concerns the semantics for $(30 \mathrm{a})$; since $(30 \mathrm{a})$ does not contain a pronoun in its complement it will simply mean that every Englishman believes whatever proposition every Frenchman believes, and so the inference will not go through. Under the approach here, on the other hand, the inference is valid because ( $30 \mathrm{a}$ ) has a meaning whereby the free relative in object position can be taken to range over properties, and so (30a) can mean that every Englishman stands in the z(believe') relation to whatever property every Frenchman stands in.
} 
inference in (31) has nothing to do with de se belief. First, she points out that the ambiguity is preserved in such inference cases; I refer the reader to Reinhart's paper for a construction of the relevant cases. ${ }^{6}$ Second, Reinhart points out that we get inferences of this type in a wide variety of cases having nothing to do with belief, as for example in (32):

(32) a. John will buy whatever Bill buys.

b. Bill ${ }_{i}$ bought hisi favorite car.

c. Therefore, John $n_{i}$ will buy his favorite car

Notice that the inference in (32) follows from the general mechanics proposed here. Here we have $z\left(b u y^{\prime}\right)$ throughout, and the object NP in (32b) denotes a function from individuals to their favorite car. From this (32c) will be a valid inference from (32a) and (32b). Thus, while I have no analysis here of de se belief, we can conclude - with Reinhart - that it has nothing to do with the inference pattern in (30). Rather, the inferences in (30) and (32) all follow from the general mechanisms for binding in a variable-free semantics.

\section{ACD Reconsidered}

We are now in a position to return to the problematic ACD cases in (11):

(11) a. John kissed every woman who wanted him to.

b. John kissed every woman who thought he would.

Recall that the problem here was that the paraphrase in (12) with a simple TVP substituted in was ungrammatical and hence it appeared that this could not be a case of TVP ellipsis. Rather, the grammatical paraphrase needed a full VP, as in (13). But if it is a case of full VP ellipsis, then it would seem to involve antecedent containment, and so it was unclear how such a case could be analyzed under direct interpretation.

But of course under the variable-free approach, the VP kiss her in (13) means simply kiss'. This means that the semantic composition of (11b) can be just like that of (13), and so (11b) is indeed an instance of TVP ellipsis. To flesh this out, we can first consider how the meaning is put together for (13); this is sketched in (33). For expository ease I ignore here the fact that he in (13) is also a pronoun and will pretend that it's an ordinary name; I will thus assign it the type-lifted meaning $\lambda \mathrm{P}[\mathrm{P}(\mathrm{h})]_{:^{7}}$

\footnotetext{
6 This fact was also pointed out to me by Sandro Zucchi.

7 Cormack (1985) and Haik (1987) note that similar sentences with a full NP rather than a pronoun are quite marginal:
}

(i) ?*John kissed every woman who wanted Bill to. 
(33) kiss-her' $=$ kiss' o her' $=$ kiss'

would-kiss-her' $=$ would' o kiss' $=\lambda \times\left[\right.$ would' $^{\prime}\left(\right.$ kiss' $\left.\left.^{\prime}(\mathrm{x})\right)\right]$

he-would-kiss-her' $=\lambda \mathrm{P}[\mathrm{P}(\mathrm{h})] \circ \lambda \times\left[\right.$ would $\left.^{\prime}\left(\operatorname{kiss}^{\prime}(\mathrm{x})\right)\right]=$

$\lambda \times[$ would'(kiss'(x))(h)]

thought-he-would-kiss-her' $=z$ (thought' $)\left(\lambda \times\left[\right.\right.$ would' $^{\prime}\left(\right.$ kiss' $\left.\left.\left.^{\prime}(\mathrm{x})\right)(\mathrm{h})\right]\right)=$

$\lambda x\left[\right.$ thought' $^{\prime}\left(\right.$ would $^{\prime}\left(\right.$ kiss' $\left.\left.\left.^{\prime}(\mathrm{x})\right)(\mathrm{h})\right)\right]$

$w_{h}^{\prime}=\lambda \cdot P[\lambda Q[\lambda y[Q(y) \& P(y)]]]$

who-thought-he-would-kiss-her' $=$ who' (thought-he-would-kiss-her') $=$ $\lambda Q[\lambda y[Q(y) \&$ thought'(would'(kiss'(y))(h))]

In (11b) exactly the same thing happens; the only difference is that here the 2-place relation kiss' is grabbed up from the context. Thus (11b) is also an instance of TVP ellipsis, which means that these are unproblematic for direct interpretation.

If this kind of treatment is correct, then here too we would expect to get cases of this kind of TVP ellipsis where the missing TVP can be picked up from another sentence. In other words, here - as in the cases discussed in Sec. 1 - the TVP ellipsis analysis predicts that there is no real need for the "antecedent containment" phenomenon. And indeed this prediction is borne out, thus we get sentences like (34) through (36):

(34) I know which man wants Mary to kiss him, and I know which man wants her not to.

(35) John kissed Mary. But it was Sue who really wanted him to.

(36) John kissed several women. But none really wanted him to.

In (36), for example, the TVP-meaning kiss' is picked up from the previous sentence. Here want type-shifts such that it means $z$ (want'), and so the subject none will bind the object slot of kiss. ${ }^{8}$

Notice that examples of this type also run counter to the claim in Sag (1976) discussed earlier (see also Hardt, this volume for discussion). Recall that Sag

(ii) ?*John kissed every woman who thought that Bill would.

I don't know why this is so, but it appears to have nothing to do with the fact that he (or him) in (11) can itself be a bound pronoun. Thus note that (35) and (36) below are fine, even though here him cannot be a bound pronoun. In fact, these seem to be alright as long as the subject of the clause containing the "missing" TVP is destressed; thus note that even the following is much better provided that $\mathrm{John}$ is not stressed:

(ii) John kissed Mary. But it was Sue who really wanted John to.

The explanation, then, would seem to lie in the interaction of stress with TVP ellipsis.

8 Some of the examples in Hardt (this volume) are also of this type. Hardt's account of these is not exactly the same as mine, although I think that our basic claims are not incompatible. 
claimed that an LF VP containing a variable in object position cannot be copied into a position where that variable will be bound by different material as binds the variable in the antecedent VP. Were we to recast the analysis of (34) - (36) in LF terms, this "rebinding" is exactly happens here. A similar case of TVP ellipsis which follows without difficulty under this approach is an example like (37) under the sloppy reading:

(37) Tomi wanted Sue to water hisi plants, while John wanted Mary to.

Again, examples of this type were discussed by Sag (see also Partee and Bach, 1981) who claimed that they were ungrammatical. While I agree that Sag's particular cases are at least somewhat awkward under the sloppy reading, good cases of this general sort can easily be constructed, as witnessed by (37). This type of case is also handled readily under the account here. Note that under the variablefree account, the meaning of water his plants in the first clause is the 2-place relation $\lambda x$ [water'(plants-of $(x))]$. This composes with the (type-lifted) meaning of Sue, and wanted undergoes $z$; this means that Tom' will ultimately "bind" the slot occupied by the pronoun. The meaning of the second clause is put together in essentially the same way, except that the 2-place relation $\lambda x\left[\right.$ water $^{\prime}($ plants-of $\left.(x))\right]$ is picked up from the context.

There remains one question: why is it that the grammatical paraphrase for (11) is (13) and not (12)? In other words, why do we need a full syntactic VP here rather than a simple TVP? My claim is that this has nothing to do with the semantics, because a VP like kiss her means essentially the same thing as a TVP like kiss. Rather, this is a fact about English syntax. Except in extraction constructions, overt NPs are in general required in characteristic NP positions. Thus (12) is bad and (13) is good for the same reason that (38) is bad and (39) is good:

(38) *Every woman wanted him to kiss.

(39) Every woman ${ }_{i}$ wanted him to kiss her ${ }_{i}$.

The analysis here accounts for this because the type-shift rule in (17) changes the semantic type but not the syntactic category of an expression. Thus shifted think still wants a sentential complement syntactically, even though its meaning is $z$ (think') which wants a property.

\section{Further Issues: The Syntax/Semantics Mismatch}

Of course, this is not the end of the story for what is not clear under the variable-free approach is why natural languages have pronouns at all. Pronouns do indeed make some contribution to the meaning - in English, for example, they 
supply gender information - but since their contribution is minimal one might expect to find gaps instead of pronouns.

I do not have the answer to this, but let me put the issue in a somewhat different way and conclude with some remarks about the syntax/semantics mismatch under this approach. As noted in Sec. 2, the most appealing aspect of the standard approach to variables is that it seems to avoid this mismatch. Consider, for example, the most deeply embedded Ss in (14a) and (14b). These certainly appear to be of the same syntactic category since - modulo the distribution of resumptive pronouns - sentences with pronouns have the same syntactic distribution as sentences without. The advantage of the standard approach, then, is that they also have the same syntactic type, while under the variable-free approach the embedded Ss in (14a) and (14b) have different types of meanings.

Yet such an objection to the variable-free approach can be turned on its head: it appears that an approach with variables in the semantics must also countenance this kind of syntax/semantics mismatch. The reason is that, as detailed by Partee (1992) (among others), there are many sorts of expressions which behave as if they contained some kind of variable but which do not contain any overt pronoun. Moreover, Partee notes that these expressions have much the same properties as do overt pronouns, and obey much the same constraints. A good example is (40):

(40) Every basketball fan ${ }_{i}$ frequents the local ${ }_{i}$ bar to watch the NCAA playoffs.

Here local can be bound by every basketball fan, just like an overt pronoun can. In the general program here the existence of such expressions is not surprising. We can analyze the meaning of local in such a way that the NP the local bar is a function from individuals to places. In (40) under the bound reading, frequents type-shifts by $z$.

What is especially noteworthy is the fact that these kinds of expressions seem to obey the same constraints on binding as do ordinary pronouns. Partee (1992) discusses this in some detail; to take a case not discussed by her consider the socalled " $\mathrm{i}$-within- $\mathrm{i}$ " condition exemplified by the contrasts in (41):

(41) a. the woman ${ }_{i}$ who married her ${ }_{i}$ childhood friend

b. the wife of John's childhood friend

c. *the wife; of heri childhood friend

As shown by (41a), a pronoun within a relative clause can be bound by the subject of that relative clause. But (41c) shows that a pronoun within the complement of a relational known like wife cannot be bound within that NP. Thus the common noun wife of John's childhood friend can have the meaning represented in (42a), but wife of her childhood friend cannot have the meaning represented in (42b): 
(42) a. wife-of'(childhood-friend-of'(j))

b. $\lambda x[$ wife-of'(childhood-friend-of $(x))(x)]$

Just why this is so is not entirely clear: if a relational noun like wife in the sentences above denotes a relation of type $\langle e,\langle e, t\rangle\rangle$ then it should be able to undergo $z$ in such a way that its last argument slot binds into its first argument. (Note that the $\mathrm{i}$-within-i condition is equally mysterious under any other account of variable-binding; the problem here is not unique to the variable-free approach.) The important point, however, is that the same constraint holds with expressions like local, nearby, across the street, etc. This is shown by the contrasts in (43) and (44), which contrasts are strikingly robust:

(43) a. The $\operatorname{man}_{i}$ who owns a local $/$ / nearby $y_{i}$ bar can get a drink anytime.

b. *The owner $\mathrm{i}_{\mathrm{i}}$ of a local $\mathrm{i} /$ nearby $_{\mathrm{i}}$ bar can get a drink anytime.

(44) a. Every mani who owns a bar across the street ${ }_{i}$ can get a drink anytime.

b. *Every owner $\mathrm{i}_{\mathrm{i}}$ of a bar across the street $\mathrm{i}_{\mathrm{i}}$ can get a drink anytime.

In (44b), for example, across the street cannot be bound by the bar-owner, but only by someone else (most likely the speaker). It appears, then, that expressions with overt pronouns and functional expressions without overt pronouns pattern sufficiently alike that any theory should account for the binding of these by the same mechanisms. But if this conclusion is correct, then one of two things must be true. Either expressions which don't contain overt pronouns in the syntax always contain hidden pronouns or variables or - as I am suggesting here - overt pronouns function more or less like gaps. Either way, there is a mismatch between the semantics and the surface (or, visible) syntax. (Moreover, it is not entirely true that sentences with pronouns have exactly the same distribution as those with full NPs in the corresponding positions. The most obvious counterexample to this generalization concerns the distribution of sentences with resumptive pronouns. These can occur in relative clauses - where sentences with gaps are also allowed but full NPs cannot (in general) be substituted in to the position of the resumptive pronoun.)

Finally, let us return to $\mathrm{ACD}$, and consider one more question about the syntax. This question is: why is something like (3) actually good?

John will read every book which Bill (also) will

The mystery here is that a relative pronoun like which usually requires syntactically a constituent with an NP gap. Indeed, in most non-movement accounts it subcategorizes for such a constituent. But here - although there is a missing VP there is no NP gap. Again I don't have a full answer to this, but we can note that this problem is completely independent of the analysis here, and arises equally well under the LF view. In fact, something like (4) is especially problematic for a 
movement analysis of $w h$ constructions, since there doesn't seem to be anywhere that which could have moved from. What a movement account would apparently have to do is to posit a structure empty VP following will where this VP contains a trace in object position bound by which. Thus the structure would have to be roughly as in (45):

\section{(45) John will read [NP every book which Bill will [vP [v e] [NP t]]]}

Interestingly enough, this ends up being a version of the TVP ellipsis analysis, since all that will need to be copied in is a TVP which will be copied into the empty $\mathrm{V}$ position.

But leaving aside the question of just what a movement analysis would say, I suspect that the solution is that a relative pronoun like which does not actually always require a constituent with an NP gap. After all, we also get cases with resumptive pronouns and no gaps. Even more relevant here, we can also get constituents without NP gaps in cases like the following: ${ }^{9}$

(46) I did everything that/which you told me.

(47) He ate everything that/which I had hoped.

There are, thus, a number of unresolved questions about the syntax of ACD, but many of these are quite independent of the analysis here. Nonetheless, it is clear that in a variable-free account, the semantics of ACD is quite straightforward. No LF is needed to account for this phenomenon, and thus this phenomenon is perfectly compatible with a theory with direct model-theoretic interpretation of surface structures. Since ACD has often been taken as one of the major stumbling blocks to such a theory, this would appear to give one more piece of evidence that such a view is tenable.

\section{References}

Bouton, Lawrence, 1970, "Antecedent-contained Pro-forms", Papers from the 6th Regional Meeting, Chicago Linguistic Society, Chicago: Chicago Linguistic Society, 154-165.

\footnotetext{
${ }^{9}$ Greg Carlson has pointed out to me that cases like this cannot all be analyzed as involving Null Complement Anaphora. This is demonstrated by (i); note that hope does not normally allow Null Complement Anaphora:
}

(i) I hope to eat cake tonight, and Bill also hopes.

Notice that these also cannot be analyzed as containing ordinary NP gaps, since hope does not take an ordinary NP complement. 
Chierchia, Gennaro, 1984, Topics in the Syntax and Semantics of Infinitives and Gerunds. Ph.D. Dissertation, University of Massachusetts. Distributed by GLSA, Linguistics Department, Amherst: University of Massachusetts.

Chierchia, Gennaro, 1990, "Anaphora and Attitudes Se Se", in R. Bartsch et al. (eds.), Language in Action, Dordrecht: Foris.

Cormack, Annabel, 1985, "VP Anaphora: Variables and Scope", in F. Landman and F. Veltman (eds.), Varieties of Formal Semantics, Dordrecht: Foris.

Dalrymple, Mary, Stuart Shieber, and Fernando Pereira, 1991, "Ellipsis and Higher Order Unification", Linguistics and Philosophy 14.

Dowty, David, 1992, "'Variable-Free' Syntax, Variable-Binding Syntax, The Natural Deduction Lambek Calculus, and the Crossover Constraint", in Proceedings of the 11th Meeting of the West Coast Conference on Formal Semantics, Stanford: CSLI Publications.

Engdahl, Elisabet, 1986, Constituent Questions. Dordrecht: D. Reidel Publishing Co.

Evans, Frederic, 1988, "Binding into Anaphoric Verb Phrases", in J. Powers and $\mathrm{K}$. de Jong (eds.), Proceedings of the 5th Annual Eastern States Conference on Linguistics, 122-129.

Fodor, Janet and Ivan Sag, 1982, "Referential and Quantificational Indefinites", Linguistics and Philosophy 5, 355-398.

Geach, Peter, 1962. Reference and Generality. Ithaca: Cornell University Press.

Ginzburg, Jonathan, 1992. Questions, queries, and facts: a semantics and pragmatics for interrogatives. Ph.D. Dissertation, Stanford.

Groenendijk, Jeroen and Martin Stokhof, 1983, "Interrogative Quantifiers and Skolem Functions", in K. Ehlich and H. van Riemsdijk (eds.), Connectedness in Sentence, Discourse and Text, Tilburg Studies in Language and Literature 4, Tilburg University.

Haik, Isabelle, 1987, "Bound VPs that Need to Be", Linguistics and Philosophy 18.

Hankamer, Jorge and Ivan Sag, 1976, "Deep and Surface Anaphora", Linguistic Inquiry 7.

Handt, Daniel, this volume, "A Semantic Theory of VP Ellipsis".

Hepple, Mark, 1990, The Grammar and Processing of Order and Dependency: A Categorial Approach. Ph.D. Dissertation, University of Edinburgh.

Higginbotham, James, 1992, "Reference and Control", in R. Larson et al. (eds.), Control and Grammatical Theory. Dordrecht: Kluwer.

Hornstein, Norbert, 1984, Logic as Grammar. Cambridge: MIT Press.

Jacobson, Pauline, 1991a, "Antecedent Contained Deletion without Logical Form", presented at the Annual Meeting of the Linguistic Society of America, Chicago.

Jacobson, Pauline, 1991b, "Paycheck Pronouns, Functional Questions, and Variable Binding", presented at the ASL/LSA Conference on Language and Logic, Santa Cruz. 
Jacobson, Pauline, 1992a, "Flexible Categorial Grammars: Questions and Prospects" in R. Levine (ed.), Formal Grammar: Theory and Implementation, UBC Press.

Jacobson, Pauline, 1992b, "Bach-Peters Sentences in a Variable-Free Semantics", in Proceedings of the 8th Amsterdam Colloquium, Amsterdam: ITLI.

Jacobson, Pauline, 1992c, "Raising without Movement", in R. Larson et al. (eds.), Control and Grammatical Theory. Dordrecht: Kluwer.

Keenan, Edward, 1971, "Names, Quantifiers, and a Solution to the Sloppy Identity Problem", Papers in Linguistics 4.

Ladusaw, William, 1979. Polarity Sensitivity as Inherent Scope Relations. Ph.D. Dissertation, University of Texas. Published by Garland Publishing, Inc., 1981.

Landman, Fred and Ieke Moerdijk, 1983, "Compositionality and the Analysis of Anaphora", Linguistics and Philosophy 6, 89-114.

Larson, Richard and Robert May, 1990, "Antecedent Containment or Vacuous Movement: Reply to Baltin", Linguistic Inquiry 21, 103-122.

Levin, Nancy, 1979. Main Verb Ellipsis in Spoken English. Ph.D. Dissertation, Ohio State University. Published in A. Zwicky (ed.), Clitics and Ellipsis, Ohio State Working Papers in Linguistics 24, Columbus, 65-165.

Lewis, David, 1979, "Attitudes de-dicto and de-se", The Philosophical Review 88.

Partee, Barbara, 1985, "Ambiguous Pseudo-Clefts with Unambiguous $B e^{\prime \prime}$ in S. Berman, J-W. Choe, and J. McDonough (eds.), Proceedings of NELS 16, 354-367. Distributed by GLSA, Amherst: University of Massachusetts.

Partee, Barbara, 1992, "Anaphoric and Deictic Pieces of Meaning", in Proceedings of the 8th Amsterdam Colloquium. Amsterdam: ITLI.

Partee, Barbara and Emmon Bach, 1981, "Quantification, Pronouns, and VP Anaphora", in J. Groenendijk, T. Janssen, and M. Stokhof (eds.), Formal Methods in the Study of Language: Proceedings of the Third Amsterdam Colloquium. Amsterdam: Mathematisch Centrum.

Pollard, Carl and Ivan Sag, 1982, "Reflexives and Reciprocals in English: An Alternative to the binding Theory", in Proceedings of the 2 nd West Coast Conference on Formal Linguistics, 189-203.

Pollard, Carl and Ivan Sag, to appear. Head Driven Phrase Structure Grammar. Chicago: University of Chicago Press and Stanford: CSLI Publications.

Quine, W.V., 1966, "Variables Explained Away", in Selected Logic Papers. New York: Random House, 227-235.

Reinhart, 1990, "Self Representation", presented at the Princeton Conference on Anaphora.

Sag, Ivan, 1976. Deletion and Logical Form. Ph.D. Dissertation, MIT. Published by Garland Publishing, Inc.

Steedman, Mark, 1987, "Combinatory Grammars and Parasitic Gaps", Natural Language and Linguistic Theory 5b, 403-440. 
Szabolcsi, Anna, 1987, "Bound Variables in Syntax: Are There Any?", in J. Groenendijk et al. (eds.), Proceedings of the 6th Amsterdam Colloquium. Amsterdam: ITLI.

Szabolcsi, Anna, to appear, "Combinatory Categorial Grammar and Projection from the Lexicon", in I. Sag and A. Szabolcsi (eds.), Lexical Matters. Stanford: CSLI Publications.

Williams, Edwin, 1977, "Discourse and Logical Form", Linguistic Inquiry 8.

Williams, Edwin, 1983, "Semantic vs. Syntactic Categories", Linguistics and Philosophy 6, 423-446.

\section{Pauline Jacobson}

Department of Cognitive and Linguistic Sciences

Box 1978

Brown University

Providence, RI 02912

LI700013@brownvm (bitnet) 
